\title{
Identification of allopatric clades in the cosmopolitan ophiuroid species complex Amphipholis squamata (Echinodermata). The end of a paradox?
}

\author{
Mickaël Le Gac ${ }^{1,4}$, Jean-Pierre Féral ${ }^{1}$, Elie Poulin ${ }^{2}$, Mélanie Veyret ${ }^{1}$, Anne Chenuil ${ }^{3, *}$ \\ ${ }^{1}$ Observatoire Océanologique de Banyuls, CNRS UMR7628, BP 44, 66651 Banyuls-sur-Mer cédex, France \\ ${ }^{2}$ Departamento de Ciencias Ecológicas, Facultad de Ciencias, Universidad de Chile, Las Palmeras 3425, Casilla 653, \\ Nuñoa, Santiago, Chile \\ ${ }^{3}$ Centre d'Océanologie de Marseille, Rue de la batterie des Lions, DIMAR, UMR 6540-CNRS, 13007 Marseille, France \\ ${ }^{4}$ Present address: UMR 8079, Ecologie, Systématique et Evolution, Université Paris-Sud, Bâtiment 360, 91405 Orsay cédex, France
}

\begin{abstract}
Life history traits (absence of larval phase, small size and hermaphroditism) do not predispose Amphipholis squamata to dispersal, yet paradoxically it has a nearly cosmopolitan distribution. Recent phylogenetic analyses of 16S mitochondrial DNA (mt-DNA) sequences revealed that (1) Amphipholis squamata is a complex of diverging clades, each of them being found in the North Atlantic as well as in the South Pacific Ocean, and (2) genetic structure is low along the coasts of New Zealand, leading the authors to conclude that rafting may allow important gene flow in this taxon and possibly worldwide distribution of species. For the present study, we obtained 16S mt-DNA sequences from individuals of the Mediterranean Sea, which we analysed along with published data. We show that several sub-clades of previously identified clades display an allopatric distribution, either Atlantic versus Mediterranean, or Mediterranean and Atlantic versus New Zealand. Furthermore, none of the haplotypes (from any sub-clade) have been found in both Mediterranean and Atlantic samples. These results establish that at least some species of the A. squamata complex, and possibly all of them, lack inter-oceanic or even Atlantic-Mediterranean distributions. We suggest that the worldwide distribution of some clades only reflects the antiquity of the clades, which are composed of several species.
\end{abstract}

KEY WORDS: Species complex · Cryptic species $\cdot$ Marine realm $\cdot$ Dispersal $\cdot$ Colour polymorphism Resale or republication not permitted without written consent of the publisher

\section{INTRODUCTION}

The small hermaphrodite ophiuroid Amphipholis squamata (Delle Chiaje, 1828) has long been regarded as a cosmopolitan species. It is found in all oceans, except the Southern Ocean, in a wide range of habitats, from the subsurface to $1300 \mathrm{~m}$ (Gage et al. 1983, Hendler 1995). In many marine benthic invertebrates, dispersal only occurs during the larval phase, but development of A. squamata does not have a free stage. Early development occurs inside adult bursae. Moreover, adults are small (1 to $3 \mathrm{~mm}$ in disc diameter) and live in cryptic habitats (under stones, in rock clefts among or in crevices of algae), a mode of life that does not generally allow long distance gene flow. Thus, there is a paradox of an extremely wide distribution for a species that lacks a free larval stage and whose adults are devoid of widespread dispersal abilities. However, A. squamata has been observed in mats of floating algae (Highsmith 1985, Alva \& Vadon 1989) and therefore may disperse by rafting. No diagnostic morphological (structural) variation has been found among geographical areas or among colour varieties (see below).

Amphipholis squamata is a polychromatic taxon, displaying several colour patterns on the disc and arms (Deheyn et al. 1997). Based on physiological traits and progeny analyses at a local scale, Deheyn and co- 
workers hypothesized that some colour varieties (black and beige) were reproductively isolated sibling species, since progeny always display the colour of the adult in which they developed (Deheyn \& Jangoux 1999, Deheyn et al. 2000). Two independent studies of populations from Sicily and Banyuls-sur-Mer (Mediterranean Sea) using Random Amplified Polymorphic DNA (RAPD) revealed strong genetic differentiation between 4 or 5 colour morphs (Féral et al. 2001, 2003). Within the widespread spotted colour morph, genetic differentiation among seas (English Channel, Mediterranean Sea, Pacific Ocean) appeared very high (Dupont et al. 2000). Finally, data from 16S mt-DNA and Internal Transcribed Spacer (ITS) rDNA in Brittany did not confirm the hypothesis that colour morphs belong to distinct species since each colour variety was found in several highly divergent genetic groups (Sponer et al. 2001), except for a cluster of 5 orange individuals.

First studies of genetic variability within Amphipholis squamata found very large divergences between individuals from distant parts of the world (Murray 1989, Sponer \& Roy 1999), comparable to that observed between distinct genera of holothuroids. These results, obtained from few individuals, suggested that $A$. squamata may be a complex of sibling species.

Other studies, made at local scales, found a very important genetic divergence between individuals from the same sample or very close to one another in natural surroundings: 2 to $3 \mathrm{~km}$ (Poulin et al. 1999), $100 \mathrm{~m}$ (Sponer et al. 2001), and less than $1 \mathrm{~m}$ (Féral et al. 2003, E. Poulin et al. unpubl. data). Sponer et al. (2001) identified 2 very divergent clades (named A and B) within Amphipholis squamata of the English Channel (Roscoff, Brittany, France), using 16S mt-DNA and Internal Transcribed Spacers of nuclear rDNA. These clades did not seem to hybridize (or at least, not widely) in Brittany since there was total congruence between mitochondrial and nuclear markers in the 23 individuals analysed. Sponer \& Roy (2002), investigating 16S mt-DNA diversity all around New Zealand, found 4 very divergent clades in syntopy, among which were the clades previously found in the English Channel (A and B). Thus, although distinct taxa were clearly identified within A. squamata, the paradox is not resolved since the identified clades are widely distributed. Allopatric monophyletic groups of haplotypes have not yet been found. One explanation, favoured by the authors, is that significant dispersal possibilities exist even in the absence of active dispersal capacities, namely by rafting on macroalgae (Highsmith 1985). However, though rafting is not unlikely, the observation of low but significant genetic structuration of populations around New Zealand correlated with marine biogeographic zones suggests that at least partial barriers to dispersal exist at a regional scale. Together with the significant level of divergence observed between clades, this suggests that the cosmopolitan clades identified may be composed of several species, which, for some of them, may be allopatrically distributed and have narrower geographic ranges.

In order to investigate this hypothesis, we present a study combining data ranging from local to worldwide scales. We obtained 16S mt-DNA sequences from Mediterranean samples and analyzed phylogenies and networks of haplotypes combining Mediterranean, Atlantic (Sponer et al. 2001) and Pacific haplotypes (Sponer \& Roy 2002). Our results show that even within clades, there are distinct monophyletic groups (subclades) corresponding to distinct geographic origins, thereby defining allopatric groups of haplotypes and establishing that strong barriers to gene flow exist within the species complex of Amphipholis squamata.

\section{MATERIALS AND METHODS}

Amphipholis squamata individuals were sampled from blocks of the calcareous alga Corallina officinalis at Banyuls-sur-Mer, Mediterranean Sea, France. Blocks were collected by snorkelling (0 to $1 \mathrm{~m}$ depth) during March and April 2002. Distance between sampling sites did not exceed $20 \mathrm{~m}$. For retrieval of specimens, calcareous concretions were crushed and ophiuroids extracted by hand.

All the specimens collected (680) were photographed a few hours after sampling, allowing us to define 9 classes (including one undetermined) taking into account body and arm colours. Our classes do not necessarily correspond to the colour varieties of Deheyn et al. (2000) whose classification does not seem universal.

Molecular methods. We used Chelex $100^{\circledR}$ (Walsh et al. 1991) to extract DNA from Amphipholis squamata. An arm from each ophiuroid was incubated at $65^{\circ} \mathrm{C}$ for 3 to $4 \mathrm{~h}$ in $500 \mu \mathrm{l}$ of a Chelex $10 \%$ aqueous solution. Subsequently, the solution was boiled for $10 \mathrm{~min}$ and then stored at $-20^{\circ} \mathrm{C}$.

We amplified about $400 \mathrm{bp}$ of the mt-DNA gene $16 \mathrm{~S}$ rRNA for about 370 individuals. One $\mu$ of the DNA extraction solution was used for each PCR amplification. Primers 16SF2 (5'-GTTTCGGTTTACCAAAAACAT-3') and 16SR2 (5'-AGGTTTTTCTGATCCAACATCG-3') were used for PCR and sequencing. Amplification was performed using the following conditions; initial denaturation for $5 \mathrm{~min}$ at $94^{\circ} \mathrm{C}, 40$ cycles of $40 \mathrm{~s}$ at $94^{\circ} \mathrm{C}$, $30 \mathrm{~s}$ at $60^{\circ} \mathrm{C}$ and $2 \mathrm{~min}$ at $72^{\circ} \mathrm{C}$. PCR products were purified before sequencing, using MiniElute columns (Qiagen). Sequencing was performed by the Qbiogen Company for 33 individuals (32 from Banyuls-sur-Mer and 1 from the Tindari Lagoon (Sicily, Italy) which was 
collected during a previous study). All sequences have been submitted to GenBank (accession numbers AY248758 to AY248770). Sequences obtained by Sponer et al. (2001) (11 haplotypes corresponding to 23 individuals from Roscoff [English Channel, France], 1 haplotype from Hawaii [USA, Pacific Ocean] and 1 from Sidney [Australia, Pacific Ocean]; accession numbers AF331166 to AF331190) and by Sponer \& Roy (2002) (40 haplotypes corresponding to 173 individuals from New Zealand [Pacific Ocean]; accession numbers AF522464 to AF522503) were also used in our study. Alignment was done using Clustal X (Thompson et al. 1997) and corrected by hand.

Using sequence data, we determined a restriction enzyme (HinfI) which distinguished between individuals from clades A and B (Sponer et al. 2001). After digestion of $5 \mu \mathrm{l}$ of PCR product in a volume of $10 \mu \mathrm{l}$, 382 individuals from Banyuls-sur-Mer were characterized by electrophoresis on $2 \%$ agarose gels.

Data analyses. Phylogenetic relationships between Amphipholis squamata haplotypes were investigated using Neighbour Joining (NJ), Maximum Parsimony (MP) and Maximum Likelihood (ML) methods. The Modeltest program (Posada \& Crandall 1998) was used to determine the evolution model which best fitted our data. This program compares different nested models of DNA substitution. It calculates the likelihood ratio test distribution in order to reject different null hypotheses about the process of DNA substitution.

MP, ML and NJ analyses were conducted with PAUP version 4.0b10 (Swofford 2002). The following options were employed for MP analyses: heuristic search, characters unordered with equal weight, starting tree obtained via stepwise addition option and constructed with random sequence addition (10 replicates), branch swapping by TBR (tree bisection reconnection). Two distance matrices were compared for NJ reconstructions, the distance inferred from the model of evolution determined by Modeltest, and the logdet distance (Lockhart et al. 1994, \#345) which is important when base composition varies according to lineage and is not tested by Modeltest. Bootstrap confidence values were calculated from 1000 pseudoreplicates (Felsenstein 1985).

Four ophiuroid species were used as outgroups for comparison to Amphipholis squamata haplotypes: Ophiopholis aculeata, Ophiothrix quinquemaculata, Ophiothrix fragilis and Ophiura signata (GenBank accession numbers: U60198, AJ002795, AJ002789 to AJ002794, U60199). After deep branchings were established with these outgroups, analyses were performed without these genera, in order to retain more sites.

We used the TCS software (Clément et al. 2000) to build an unrooted parsimony network of haplotypes. TCS calculates the most parsimonious network at the
$95 \%$ confidence level, estimates gene genealogies and allows the presence of ancestral haplotypes in extant populations (contrary to traditional methods of phylogeny reconstruction) which is more realistic for intraspecific haplotype comparisons.

To test the null hypothesis that colour classes were independent of haplotype group (i.e. corresponding to clade A or B), we built a contingency table containing the number of individuals belonging to major colour classes and haplotype groups A and B, and used the 'Struc' program (Exact test) of the Genepop software (Raymond \& Rousset 1995).

\section{RESULTS}

We found a non-homogeneous distribution of Amphipholis squamata (similar to that found by Sponer \& Roy 2002). Numbers of individuals recovered varyied between 0 and 307 among 5 sampling sites of the same surface $(50 \mathrm{~cm} \times 50 \mathrm{~cm})$.

\section{Haplotype phylogeny}

There were 61 different haplotypes for the sequenced fragment of $16 \mathrm{~S}$ mt-DNA, among the 233 individuals analysed (Table 1): 12 haplotypes among the 32 individuals from Banyuls-sur-Mer, 11 haplotypes among the 23 individuals from Roscoff sequenced by Sponer et al. (2001), 35 haplotypes among the New Zealand individuals sequenced by Sponer \& Roy (2002) (their 40 haplotypes correspond to 35 distinct haplotypes when aligned with our slightly shorter sequences); 1 haplotype from Tindari, 1 from Sydney and 1 from Hawaii were also used. Names used for clades are the same as in Sponer et al. (2001) and Sponer \& Roy (2002). Two haplotypes were excluded from the analyses because of low quality sequences (GenBank accession numbers AY248758 and AY248764.

Table 1. Distribution of specimens and haplotypes per lineage and locality

\begin{tabular}{|llcc|}
\hline Lineage & Locality & $\begin{array}{c}\text { Number of } \\
\text { specimens }\end{array}$ & $\begin{array}{c}\text { Number of } \\
\text { haplotypes }\end{array}$ \\
\hline A1234 & Banyuls-sur-Mer & 3 & 1 \\
& New Zealand & 123 & 23 \\
& Roscoff & 13 & 6 \\
A5 & Banyuls-sur-Mer & 20 & 8 \\
& New Zealand & 0 & 0 \\
& Roscoff & 4 & 4 \\
B & Banyuls-sur-Mer & 9 & 3 \\
& New Zealand & 32 & 8 \\
& Roscoff & 6 & 1 \\
\hline
\end{tabular}


Regardless of which reconstruction method we used our results for the global tree (not shown) agree with Sponer et al. (2001) and Sponer \& Roy (2002) with strong support for the existence of 6 deep clades and, in particular, $100 \%$ bootstrap values for monophyly of each of clades A and B. Since clades C, D and E contain few haplotypes, all from the Pacific Ocean, our more detailed analysis (with longer sequences from less numerous haplotypes) will focus on clades A and B. Clade A1234 describes the monophyletic group formed by the union of the 4 clades A1, A2, A3 and A4 detailed by Sponer et al. (2001). The trees obtained with the different methods were all compatible (i.e. nodes well supported in 1 tree were never incompatible with nodes which were well supported in another tree) but the different methods did not reveal the same robust clades. Fig. 1 displays the maximum likelihood tree $(-\ln L=1234.9385)$ assuming the model of sequence evolution selected by Modeltest using the likelihood ratio test ( $p<0.01$ for each hierarchy level). The model is denoted 'K81+uf+I+G' and consists of (1) dif- ferent equilibrium base frequencies: $(\mathrm{A}=0.3007, \mathrm{C}=$ $0.2070, G=0.1605, T=0.3317$ ), (2) the following substitution rate matrix: $\mathrm{A}-\mathrm{C}=1, \mathrm{~A}-\mathrm{G}=13.6549, \mathrm{~A}-\mathrm{T}=$ 3.4629, C-G = 3.4629, C-T = 13.6549, G-T = 1, (3) a proportion of 0.4759 invariant sites and (4) a shape parameter of 0.5331 for the gamma distribution describing the variability of evolutionary rate among variable sites. The model selected using the AIC criterion is also a variant of the GTR model (TVM+I+G) and gave a very similar tree. We only represent the ML tree in Fig. 1 but several other robust clades were obtained with other methods. All methods except ML gave high support for clades A and B (77\% to $100 \%$ bootstrap values). Within clade A, clade A5 was well supported by MP (77\% bootstrap value) and ML analysis, while this node obtained 58 and $43 \%$ bootstrap values respectively with NJ-logdet and NJ-Modeltest (either the lrt or the AIC model). Within clade A5, a clade consisting of haplotypes from Banyuls-sur-Mer exclusively was strongly supported by all methods (90 to $98 \%$ bootstraps for ML and NJ trees, significant branch length for ML), while

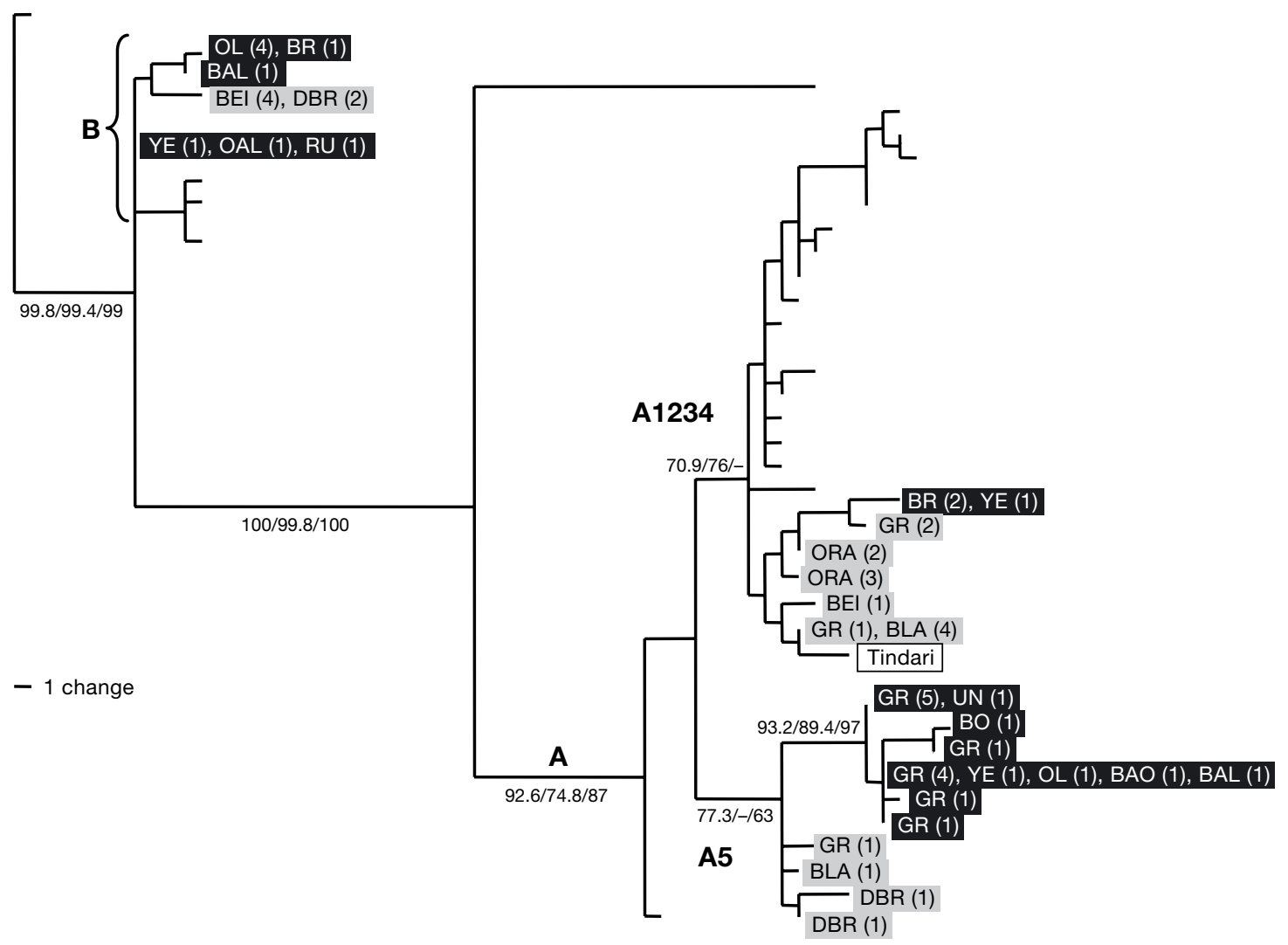

Fig. 1. Amphipholis squamata. Maximum likelihood tree of 16S mtDNA haplotypes from different regions of the world. Numbers below branches indicate high bootstrap values (in \%) obtained after 1000 replicates with MP, NJ-Modeltest and NJ-logdet methods (high bootstrap values for nodes not supported in the ML tree are discussed in 'Results'). Haplotypes from Banyuls-surMer (this study) and Roscoff (Sponer et al. 1999) are in grey and black rectangles respectively; the others are from the Pacific Ocean, except 'Tindari' (from Sicily, Mediterranean Sea). Codes for haplotypes indicate the colour (see Sponer \& Roy [1999] and Table 5), with the number of individuals in parentheses. Though clade B does not appear to be supported by the ML reconstruction, it is identified in the tree to facilitate understanding of 'Results' and 'Discussion'. Haplotype 1771fio (Sponer \& Roy 2002) was taken as the outgroup (as assessed by the global analysis) 
the clade containing all the other haplotypes, which originated from Roscoff, was supported in the NJlogdet tree ( $89 \%$ bootstrap). In clade A1234, a subclade consisting of all haplotypes from the Mediterranean and Atlantic (i.e. Roscoff and Banyuls-sur-Mer) but excluding the Pacific haplotypes was supported by the ML analysis (Fig. 1). In clade B, haplotypes from the Pacific Ocean were clustered together, separate from those of Roscoff and Banyuls in the ML analysis.

Genetic distances (K2P) were very high between haplotypes from different clades, reaching 19.4\% between haplotypes from clades A and B. Within major clades, genetic divergences could also be high (Table 2). These major clades were not restricted to a geographic area, and were found in syntopy in different parts of the world, though in different proportions $(p=0.0000$, Exact test) and very divergent $16 \mathrm{~S} \mathrm{mt-}$ DNA haplotypes were found in the same sampling locality (Table 3). Nevertheless, each particular haplotype was only found in 1 locality.

Within the main clades, however, several supported monophyletic groups corresponded to geographically homogeneous units (Fig. 1, Table 4). (1) Specimens from clade A5 (79\% bootstrap) were all from Banyuls-

Table 2. Amphipholis squamata. Kimura 2-parameter genetic distance (min-max) in \% between and within clades

\begin{tabular}{|lccc|}
\hline & A1234 & A5 & B \\
\hline A1234 & $0.29-5.5$ & $5.1-11.1$ & $13.4-19.4$ \\
A5 & & $0.29-5.2$ & $0.29-5.8$ \\
B & & & \\
\hline
\end{tabular}

Table 3. Amphipholis squamata. Kimura 2-parameter genetic distance (min-max) in \% between and within geographic area

\begin{tabular}{|lcrc|}
\hline & Banyuls & Roscoff & New Zealand \\
\hline Banyuls & $0.29-16.1$ & $1.2-16.8$ & $1.5-18.9$ \\
Roscoff & & $0.29-17.2$ & $0.29-19.5$ \\
New Zealand & & & \\
\hline
\end{tabular}

Table 4. Amphipholis squamata. Kimura 2-parameter genetic distance (min-max) in \% within clades A1234, A5 and B; between and within localities. In clade A1234, Roscoff and Banyuls are clustered because there is only 1 haplotype from Banyuls. In clade B, Roscoff and Banyuls are clustered because there is only 1 haplotype from Roscoff. There is no haplotype from New Zealand in clade A5

\begin{tabular}{|c|c|c|c|c|c|c|}
\hline & \multicolumn{2}{|c|}{$-\mathrm{A} 1234-$} & \multicolumn{2}{|c|}{$\longrightarrow \mathrm{A} 5 \longrightarrow$} & \multicolumn{2}{|c|}{$-\mathrm{B}-$} \\
\hline & $\begin{array}{l}\text { Banyuls } \\
\text { Roscoff }\end{array}$ & $\begin{array}{c}\text { New } \\
\text { Zealand }\end{array}$ & Banyuls & Roscoff & $\begin{array}{l}\text { Banyuls } \\
\text { Roscoff }\end{array}$ & $\begin{array}{c}\text { New } \\
\text { Zealand }\end{array}$ \\
\hline $\begin{array}{l}\text { Banyuls } \\
\text { Roscoff }\end{array}$ & $0.29-4.4$ & $2.6-5.4$ & $0.29-2.7$ & $\begin{array}{l}2.1-5.2 \\
0.9-1.8\end{array}$ & $0.29-1.8$ & $1.5-5.5$ \\
\hline New Zealand & & $0.29-5.5$ & & & & $0.29-5.8$ \\
\hline
\end{tabular}

sur-Mer (Mediterranean Sea) and Roscoff (Channel/ Atlantic); none were from the Pacific Ocean. (2) Haplotypes of clade A5 from each geographic area formed strongly supported monophyletic groups, namely 'A5Banyuls' and 'A5-Roscoff' (bootstrap values of 90\% and $96 \%$, respectively). (3) Within clade B, all haplotypes from Banyuls-sur-Mer and Roscoff (i.e. all locations except those from the Pacific Ocean) clustered in a monophyletic group (bootstrap value $94 \%$ for NJ tree with $\mathrm{K} 2 \mathrm{P}$, though trees obtained by parsimony reconstructions did not strongly support this clade with bootstrap values being lower than $50 \%$ ). (4) Other haplotypes from clade B (all from New Zealand) formed 2 strongly supported clades (100\% bootstrap for a 2 haplotype cluster and $87 \%$ for a group of 6 haplotypes). (5) Within clade A1234, which contains haplotypes from all locations, several sub-clades cluster haplotypes from the same locality ( 2 New Zealand clusters have bootstrap values of 83 and $85 \%$ ).

\section{Gene genealogy}

Within clade A5, haplotypes from Roscoff were separated from those of Banyuls-sur-Mer as in the phylogenetic analysis (Fig. 2), by a minimum of 6 steps. Within clade A1234, haplotypes from New Zealand formed 1 group separated from those of Roscoff and Banyuls-sur-Mer (2 distinct groups) by at least 4 steps. Within clade B, haplotypes from Banyuls-sur-Mer and Roscoff formed 1 group which was separated from those of New Zealand (2 groups) by at least 3 steps.

\section{Body colours}

The 9 colour classes were not distributed randomly among mitochondrial clades $\mathrm{A}$ and $\mathrm{B}$ (Table 5, p = 0.0000) but similar to Sponer et al. (2001), we found no absolute congruence between any body colour class and mitochondrial clade, suggesting that the statistical association between colour and genetic classes may just reflect the effect of founding events likely to occur, given the aggregative distribution and possibility of selfing of Amphipholes squamata (Poulin et al. 1999, E. Poulin et al. unpubl. data).

\section{DISCUSSION}

The fact that clades A and B correspond to distinct taxa was already established by Sponer \& Roy (2002) for 


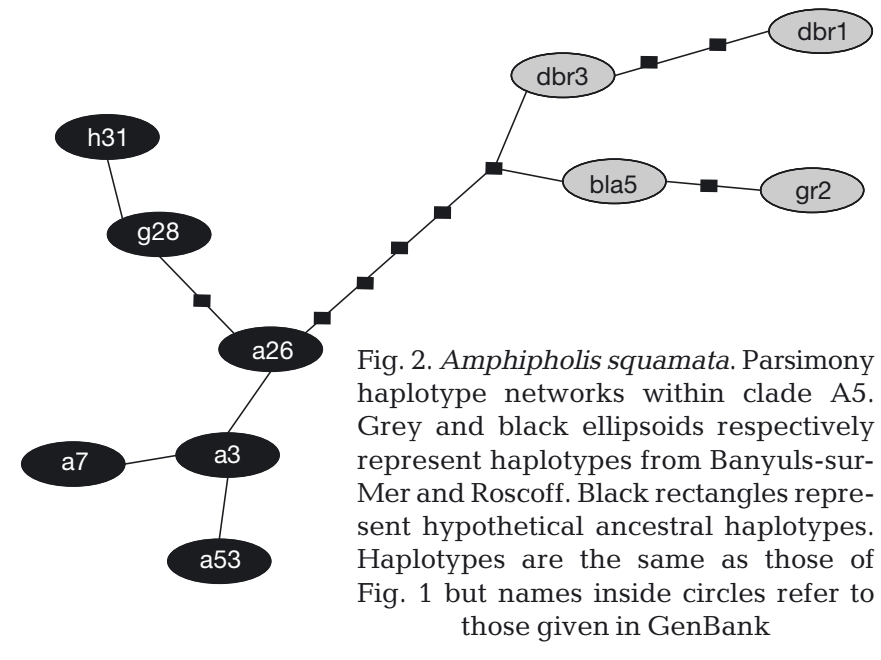

Pacific samples: 11 individuals from mitochondrial clade A and 17 from clade $B$ displayed ' $\mathrm{A}$ ' and 'B' patterns for ITS rDNA restriction profiles. This does not signify the absence of hybridisation, but it proves that even if hybrids can form, they are probably counter-selected, and genomes from both clades are not homogenised.

Several results for our mitochondrial DNA analysis support the idea that distinct genetic entities (species or sub-species which do not exchange genes) exist within each of the main clades A and B, some of which correspond to distinct geographic areas.

The 3 networks of haplotypes, built within clade A5, clade A1234 and clade B, revealed clustering of haplotypes of the same geographic origin, which was absolute in the case of clade A5 (Fig. 2). (These analyses were restricted to sets of related haplotypes.)

The phylogenetic analysis of the whole data set confirms these results and provides additional evidence for the presence of separate genetic entities within the species complex of Amphipholis squamata. The strongest evidence that some clades no longer exchange genes occurs when a monophyletic group of

Table 5. Amphipholis squamata. Distribution of individuals of the 10 colour classes in the 2 main clades

\begin{tabular}{|lrcc|}
\hline Colour morph & Clade A & Clade B & $\begin{array}{c}\text { Clade } \\
\text { unknown }\end{array}$ \\
\hline Black and orange (BO) & 5 & 0 & 0 \\
Brown (BR) & 4 & 4 & 0 \\
Brown arms - orange (BAO) & 2 & 0 & 0 \\
Brown arms - light (BAL) & 38 & 3 & 0 \\
Grey (GR) & 174 & 4 & 9 \\
Olive (OL) & 23 & 25 & 0 \\
Orange arms - light (OAL) & 14 & 4 & 1 \\
Rust (RU) & 2 & 3 & 0 \\
Yellow (YE) & 12 & 3 & 1 \\
Undetermined (UN) & 28 & 0 & 5 \\
\hline
\end{tabular}

haplotypes (by definition, a clade) is itself composed of allopatric brother clades, i.e. distinct monophyletic groups which correspond to disjunct geographic distributions. This is the case for clades 'A5-Banyulssur-Mer' and 'A5-Roscoff'. To a lesser extent, the fact that within a clade, all individuals from a given area belong to a monophyletic group also contradicts the hypothesis that genes are exchanged worldwide and instead suggests genetic isolation of this area. This is the case of (1) the sub-clade of clade A1234 grouping all haplotypes from the Atlantic and Mediterranean samples and (2) the sub-clade of clade B grouping all the haplotypes from the Pacific Ocean, which both appear in the ML tree. Finally, the fact that 1 clade is represented by individuals from a restricted geographic area strongly suggests, if the number of haplotypes is sufficient, that this clade is genetically separated from other ones. This is the case for clade A5 (its 13 distinct haplotypes all come from the Atlantic and Mediterranean samples [21 individuals]).

Furthermore, each of the 60 haplotypes is geographically restricted to only 1 of the 3 main sampling locations (Roscoff, Banyuls-sur-Mer, or New Zealand). This is striking evidence of interrupted gene flow.

Monophyly and absence of intermediate haplotypes among supported monophyletic groups does not prove that the groups are separate species. It does not even prove that the entities were once separated (though they may have hybridised), since past demographic bottlenecks may have created discrepancies in the coalescent tree of haplotypes. However, it may be instructive to compare observed divergence levels and nucleotidic diversity with data available from other species for the same molecule. Several studies using $16 \mathrm{~S}$ or other rapidly evolving mitochondrial sequences were performed on complexes of echinoderm species, and average within-species diversity never exceeded $0.84 \%$ and usually was much lower. Pairs of echinoderm groups whose divergence levels was much lower than those observed between monophyletic groups of Amphipholis squamata (Tables 2 to 4) belonged to proven distinct species which were identified either by their morphology or by their allopatric distribution (0.4\% in Leptasterias subgenus Hexasterias, which are brooding asteroids [Hrincevich et al. 2000], 2.5\% in sea urchin Diadema spp. [Lessios et al. 2001b], 0.54\% in sea urchin Eucidaris spp. [Lessios et al. 1999]; see also Hrincevich \& Foltz (1996), Lessios et al. (1998), Lessios et al. (2001a). Since these data (except for Leptasterias) come from more widely dispersing and fecund species (with planktotrophic larvae), one might expect that drift would affect $A$. squamata more than the species described above, and therefore, the interspecific divergence threshold should be lower. Moreover, these estimates are for genes evolving more 
rapidly than $16 \mathrm{~S}$ rDNA, providing us with a conservative comparison. These comparative data would be more reliable however if we could check that $16 \mathrm{~S}$ mtDNA in Amphipholis evolves at a rate comparable to other echinoderm species, but we found no way to calibrate the molecular clock in ophiuroids, and $16 \mathrm{~S}$ mtDNA sequences are too divergent to be aligned with a common outgroup in order to perform relative rate tests.

However, the fact that several monophyletic groups have restricted geographical distributions, together with identification of allopatric brother groups, the absence of shared haplotypes between sampling locations and the high levels of divergence lead us to conclude that clades 'A5-Roscoff', 'A5-Banyuls-sur-Mer', and probably other monophyletic groups within the major clades already identified are distinct species or at least sub-species (they may also be composed of several species and represent taxa of higher levels). These new taxa allow us to demonstrate that cosmopolitism is not the rule in the Amphipholis squamata complex, which solves the paradox of allopatric clades.

The speciation events that occurred between the main clades and even some sub-clades of Amphipholis squamata (such as A1234 and A5) might be quite old. Indeed, we have shown that gene flow does not exist between sampling sites, indicating low dispersal. Given this low dispersal, a long period of time must have elapsed for clades to become cosmopolitan. Controlled crosses are required to establish whether geographically restricted sub-clades constitute biological species or just sub-species (i.e. potentially interfertile groups whose distribution ranges are disjunct leading to effective rupture of gene flow). We emphasize that none of our conclusions depends on whether or not hybridization occurs between sympatrical clades. Morphological differences remain to be found between newly defined evidenced clades. The absence of morphological variation corresponding to geographic area has been previously emphasised (Sponer \& Roy 2002) but data relating to morphological variation among mitochondrial clades, to our knowledge, has not been published. If the absence of morphological variation in mitochondrial clades was found within a species, this could be explained by hybridisation among clades or by the pressure of selection maintaining a generalist ecology (explaining why genetic divergence was not paralleled by morphological divergence).

These results resolved an old paradox (cosmopolitism of a species with non-dispersing life history traits) but generated a new one: how can we explain the fact that in a given area, some apparently habitable patches are empty, whereas others are always occupied by several taxa of the species complex? Classical metapopulation dynamics with founding events, sug- gested by high selfing rates in Amphipholes squamata (Poulin et al. 1999, E. Poulin unpubl. data) and presence of empty patches, would imply relative homogeneity within patches. This suggests that not only does competition not lead to exclusion of one taxon when another one is occupying a site (which apparently contradicts a paradigm of ecology, but may be explained by the fact that either resources are not limiting or resources are used differently among taxa), but also that individuals may survive or reproduce better in the presence of individuals of distinct taxa of the species complex. Frequency-dependent selection was previously suggested to explain colour polymorphism within A. squamata populations (distinct colour morphs could be differentially eaten by predators or susceptible to parasitism; Féral et al. 2001). However, it is clear that there are no absolute correspondences between colour morphs and mitochondrial clades (at least in clades A and B), so selection for colour polymorphism cannot explain co-existence of taxa defined by mitochondrial DNA. Ecological studies now seem necessary to shed light on the reason why different taxa are found in apparent syntopy (sensu lato). Genetic population studies carried out within different taxa with codominant markers or mitochondrial ones characterized in larger numbers of individuals, allowing comparison of recent demographic history between species, would also be valuable.

Acknowledgements. We warmly thank S. von Boletzky for improving the English manuscript and C. Rocher for efficient technical assistance.

\section{LITERATURE CITED}

Alva V, Vadon C (1989) Ophiuroids from the western coast of Africa (Namibia and Guinea-Bissau). Sci Mar 53: $827-845$

Chenuil A, Le Gac M, Thierry M (2003) Fast isolation of microsatellite loci of very diverse repeat motifs by library enrichment in echinoderm species Amphipholis squamata and Echinocardium cordatury (Technical note). Mol Ecol Notes 3:324-327

Clément M, Posada D, Crandall KA (2000) TCS: a computer program to estimate gene genealogies. Mol Ecol 9: 1657-1659

Deheyn D, Jangoux M (1999) Colour varieties as sibling species in the polychromatic ophiuroid Amphipholis squamata (Echinodermata): evidence from inheritance of body colour and luminescence characters. J Exp Mar Biol Ecol 234:219-234

Deheyn D, Mallefet J, Jangoux M (1997) Intraspecific variations of bioluminescence in a polychromatic populations of Amphipholis squamata (Echinodermata: Ophiuroidea). J Mar Biol Assoc UK 77:1213-1222

Deheyn D, Mallefet J, Jangoux M (2000) Evidence from polychromatism and bioluminescence that the cosmopolitan ophiuroid Amphipholis squamata might not represent a unique taxon. C R Acad Sci, Ser III Sci Vie 323:499-509 
Dupont S, Chaufer S, Poulin E, Féral JP, Mallefet J (2000) Is there a link between morphological, physiological and genetic variability of the ophiuroid Amphipholis squamata? Neth J Zool 50:355-363

Felsenstein J (1985) Confidence limits on phylogenies: an approach using the bootstrap. Evolution 39:783-791

Féral JP, Villard AM, Dupont S, Mallefet J (2001) Morphological, physiological and genetic variability of the ophiuroid Amphipholis squamata from the lagoon system of OliveriTindari (Sicily). In: Barker M (ed) Proc 10th Int Echinoderm Conf, Echinoderm 2000, Dunedin, NZ. Swets \& Zeitlinger Publishers, Lisse, p 261-266

Féral JP, Villard AM, Barré N, Chenuil A (2003) What is the smallest distance of genetic differentiation in the brood protecting ophiuroid Amphipholis squamata from Western Mediterranean? In: Féral JP, David B (eds) Echinoderm Research 2001, Proc 6th Eur Conf Echinoderm, Banyuls-surMer. Swets \& Zeitlinger Publishers, Lisse, p 23-27

Gage JD, Pearson M, Clark AM, Paterson GLJ, Tyler PA (1983) Echinoderms of the Rockall trough and adjacent area. I. Crinoidea, Asteroidea and Ophiuroidea. Bull Br Mus (Nat Hist) Zool 43:263-308

Galtier N, Gouy M (1995) Inferring phylogenies from DNA sequences of unequal base compositions. Proc Natl Acad Sci USA 92:11317-11321

Hendler G (1995) Class Ophiuroidea. In: Echinoderms of Florida and the Caribbean: sea stars, Sea urchins and allies. Smithsonian Institution Press, Washington, p 89-195

Highsmith (1985) floating and algal rafting as potential dispersal mechanisms in brooding invertebrates. Mar Ecol Prog Ser 25:168-179

Hrincevich AW, Foltz D (1996) Mitochondrial DNA sequence variation in a sea star (Leptasterias spp.) species complex. Mol Phylogenet Evol 6:408-415

Hrincevich AW, Axayacatl RO, Foltz DW (2000) Phylogenetic analysis of molecular lineages in a species-rich subgenus of sea stars (Leptasterias subgenus Hexasterias). Am Zool 40:365-374

Kimura M (1980) A simple method for estimating evolutionary rates of base substitutions through comparative studies of nucleotide sequences. J Mol Evol 16:111-120

Lessios HA, Kessing BD, Robertson DR (1998) Massive gene flow across the world's most potent marine biogeographic barrier. Proc R Soc Lond Ser B Biol Sci 265:583-588

Lessios HA, Kessing BD, Robertson DR, Paulay G (1999) Phylogeography of the pantropical sea urchin Eucidaris in relation to land barriers and ocean currents. Evolution 53: 806-817

Editorial responsibility: John Dolan (Contributing Editor), Villefranche-sur-Mer, France
Lessios HA, Garrido MJ, Kessing BD (2001a) Demographic history of Diadema antillarum, a keystone herbivore on caribbean reefs. Proc R Soc Lond Ser Biol Sci B 268:1-7

Lessios HA, Kessing BD, Pearse JS (2001b) Population structure and speciation in tropical seas: global phylogeography of the sea urchin Diadema. Evolution 55:955-975

Lockhart PJ, Steel MA, Hendy MD, Penny D (1994) Recovering evolutionary trees under a more realistic model of sequence evolution. Mol Biol Evol 11:605-612

Murray DR (1989) Macrogeographic genetic variation in the cosmopolitan brooding brittle star, Amphipholis squamata. $\mathrm{PhD}$ thesis, Mount Allison University, New Brunswick

Posada D, Crandall KA (1998) MODELTEST: testing the model of DNA substitution. Bioinformatics 14:817-818

Poulin E, Féral JP, Forensa M, Cornudella L, Alva V (1999) Selfing and outcrossing in the brood protecting ophiuroid Amphipholis squamata. In: Candia-Carnevali MD, Bonasoro F (eds) Echinoderm Research 1998: Proc 5th Eur Conf Echinoderm Milan, Italy 7-12 Sept. Balkema, Rotterdam, p 147-150

Raymond M, Rousset F (1995) An exact test for population differentiation. Evolution 49:1280-1283

Sponer R, Roy M (1999) Molecular evolution of Amphipholis squamata (Echinodermata: Ophiuroidea): high genetic differences among populations. In: Candia-Carnevali MD, Bonasoro F (eds) Echinoderm Research 1998: Proc 5th Eur Conf Echinoderm, Milan, Italy, 7-12 Sept. Balkema, Rotterdam, p 405-408

Sponer R, Roy M (2002) Phylogeographic analysis of the brooding brittle star Amphipholis squamata (Echinodermata) along the coast of New Zealand reveals high cryptic genetic variation and cryptic dispersal potential. Evolution 56:1954-1967

Sponer R, Deheyn D, Roy M (2001) Large genetic distances within a population of Amphipholis squamata (Echinodermata: Ophiuroidea) do not support colour varieties as sibling species. Mar Ecol Prog Ser 216:169-175

Swofford DL (2002) PAUP*. Phylogenetic Analysis Using Parsimony (*and Other Methods). Version 4. Sinauer Associates, Sunderland, MA

Thompson JD, Gibson TJ, Plewniak F, Jeanmougin F, Higgins DG (1997) The CLUSTAL_X windows interface: flexible strategies for multiple sequence alignment aided by quality analysis tools. Nucleic Acids Res 25:4876-82

Walsh PS, Metzger DA, Higushi R (1991) Chelex 100 as a medium for simple extraction of DNA for PCR-based typing from forensic material. Biotechniques 10:506-513

Submitted: September 1, 2003; Accepted: March 29, 2004

Proofs received from author(s): August 27, 2004 